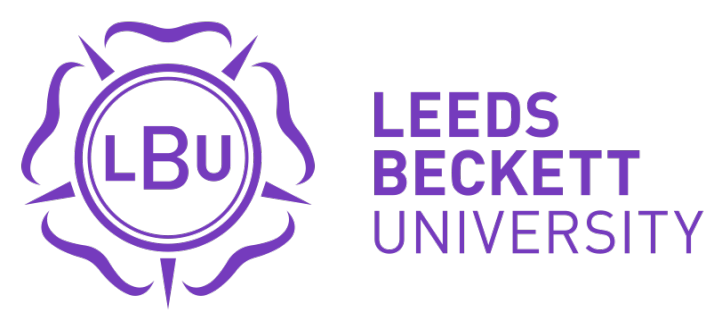

Citation:

Morgan, JA (2019) Why is there anything at all? What does it mean to be a person? Rescher on metaphysics. Journal of Critical Realism, 18 (2). pp. 169-188. ISSN 1476-7430 DOI: https://doi.org/10.1080/14767430.2019.1609287

Link to Leeds Beckett Repository record:

https://eprints.leedsbeckett.ac.uk/id/eprint/5854/

Document Version:

Article (Accepted Version)

This is an Accepted Manuscript of an article published by Taylor \& Francis in Journal of Critical Realism on 25 April 2019, available online: http://www.tandfonline.com/10.1080/14767430.2019.1609287

The aim of the Leeds Beckett Repository is to provide open access to our research, as required by funder policies and permitted by publishers and copyright law.

The Leeds Beckett repository holds a wide range of publications, each of which has been checked for copyright and the relevant embargo period has been applied by the Research Services team.

We operate on a standard take-down policy. If you are the author or publisher of an output and you would like it removed from the repository, please contact us and we will investigate on a case-by-case basis.

Each thesis in the repository has been cleared where necessary by the author for third party copyright. If you would like a thesis to be removed from the repository or believe there is an issue with copyright, please contact us on openaccess@leedsbeckett.ac.uk and we will investigate on a case-by-case basis. 


\title{
Why is there anything at all? What does it mean to be a person? Rescher on metaphysics
}

\section{Jamie Morgan}

Metaphysical Perspectives, by Nicholas Rescher, Notre Dame, University of Notre Dame Press, 2017, 258 pp., f19 (hbk), ISBN 9780268102890

\begin{abstract}
I set out key aspects of Nicholas' Rescher's Metaphysical Perspectives. I illustrate the tenor and value of the text based on extended analysis of Chapter 1 on fundamental issues of what there is and Chapter 2 on personhood. Rescher is one of the most important philosophers of the twentieth century and early twenty-first century. His works are intrinsically interesting, but also important as resources for realists working in the social sciences.
\end{abstract}

Key words Rescher, metaphysics, axiogenesis, Artificial Intelligence, personhood

"You painfully ponder what magnificent extra-terrestrial creature, enthralled with the idea of finding a simpler life, chose in the last round to become a human." (Eagleman, 2009, 12)

\section{Introduction}

What there is, why there is anything at all, how we know... these are primary foci for philosophical inquiry. They have exercised the great thinkers for thousands of years. Since the 1970s, Critical realism has been and continues to be a particularly productive and engaged framework for such questions (most recently, McWherter, 2013; 2017; 2018; with Kaidesoja, 2017; Duindam, 2018). However, critical realism has not been alone. Contemporary American pragmatism has many points of convergence with realism. Perhaps its most important proponent in the twentieth and early twenty-first century has been Nicholas Rescher (for example, Rescher, 2005). Moreover, Rescher has not just been a significant innovator within a prominent philosophical framework, narrowly pursued. During the course of a long career that began in the 1950s he has established himself as a master of his field. He has published on almost every major branch of philosophical inquiry. The former (an American pragmatist framework), of course, goes some way to explaining the potential for the latter (coverage), since development of a system of thought lends itself to application to relevant domains, and every domain is relevant if one begins from the basics. Still, potential is no guarantor of pursuit or achievement. Rescher has been prolific and throughout his career has maintained a laudable commitment to clarity. One might think this was a given in philosophy, but it is not, if by commitment to clarity one means intention to be readily comprehensible, and so widely understood. Again, chicken and egg conundrums notwithstanding, one might attribute this to his (broadly realist) pragmatism.

Rescher uses formal logical expression sparingly and only for the purposes of concision in demonstration for summary of argument. Any literate person can read one of Rescher's books. And many want to because they are singularly satisfying. They typically exhibit an 
evocative intellectual vibrancy that is unusual in the field. One cannot read a Rescher book passively. Each is like a gym for the mind, a most pleasing experience of engagement that induces a warm amniotic sensation of well-earned serotonin. To those who have not read Rescher this may seem oleaginous, to which I can only respond, read a few of his books (perhaps, Rescher, 1995; 1998a; 1998b; 2006). This brings us to Metaphysical Perspectives (2017; which can be read in conjunction with Rescher, 2018a). In this book Rescher ranges across the most fundamental issues in philosophy.

Metaphysical Perspectives is worthy of attention for various reasons. Its subject matter is intrinsically interesting, but also useful to and (in some ways) important for realists. It epitomises well-conceived structure for coherent claims and this is a skill that many social scientists can usefully emulate. As such, allowing that it demonstrates the highest standards, it might be read as a practical guide for argumentation. Concomitantly, it provides a resource for specific forms of argument on many subjects that one might draw on and fruitfully engage with. I illustrate this using the introduction, Chapter 1 on fundamentals and Chapter 14 on personhood.

\section{Locating metaphysics as philosophical inquiry: non-trivial philosophising}

By way of context, Rescher states in the preface that:

Metaphysics is the study of existence at the highest level of generality. Its concern is with the 'big questions' regarding the world, ourselves, and our place within reality's scheme of things. The salient task of the field is to elucidate the concepts and principles by whose means a clearer understanding of the ideas of existence and reality can be achieved... the book deals with a range of key metaphysical issues [exploring aspects of the subjects] three prime areas of concern: 1 ) the world as such... 2) ourselves as nature's denizens and our potential for learning about it, and 3) the transcendent domain of possibility and value, which impels us to consider issues that reach beyond the resources of nature... [the book] sets out an integrated view of the key philosophical problems (Rescher, 2017, ix).

This first statement makes it clear that metaphysics is a primary focus for philosophical enquiry. It encompasses the 'big questions' about the 'scheme of things'. As such, it embraces, without blurring or conflation matters that can be decomposed along (amongst others) ontological, epistemological, naturalistic and idealist lines, subject to definition for given distinctions. Rescher has made clear over the decades that his own approach is neither pejoratively foundational nor reductive concerning these matters. He is a systematic thinker in the most positive sense of the term. He states positions, concepts etc and then presses them according to different lines of reasoning from which arise inferences and claims regarding those positions, claims and their subject matters. From this systematic process, he develops substantive systems of thought: how one can think about this or that, what we can claim about this or that, and so forth. Metaphysical Perspectives follows this same format. Rescher's work is neither sceptical to no purpose nor self-cannibalising of reason. It is 
systematic to some constructive (constructed) purpose. Since the purpose here is fundamental, Rescher begins by locating metaphysics in terms of philosophy in general.

Accordingly, in the introductory chapter of Metaphysical Perspectives Rescher first sets out a schematic of how inquiry productively proceeds. Philosophy can be categorised according to four different conceptions of philosophy as an activity, and this is followed by different sets of questions or objectives, and a host of potential categories of error that can be committed (Rescher, 2017, 1-8). The four identified categories of philosophy as activity are:

1. Philosophy as literature: ideas as episodic stimulation of thought for the individual or as communication for the group as a means to propagate a form of culture that valorises ideas;

2. Philosophy as mega-science or companion to science: science is characterised as seeking understanding of constituents and processes of the natural and social world and philosophy is characterised as an exploration of the scope and limits of cognitive efforts and practical activities within the world that science (in so far as it is adequate) describes;

3. Philosophy as normative assessor: philosophy is not restricted to what is in some static reductive sense, but rather involves a primary concern with questions of value, both cognitive (what we deem important) and practical (what we deem useful under some description), matters that we, in some sense, derive from the world but also put or pour into it, typically explored as axiological;

4. Philosophy as life coach: philosophy ought to provide relevant guidance for conduct (and typically some concept of the "good life").

The latter three may seem constitutive in a way the first does not. Moreover, for a realist, the latter three seem to be mutually implicated. Rescher's only point here is to suggest that philosophers tend to restrict themselves to one of these four activities, but ought to range across all of them. 'Key questions at the heart of the discipline' include (Rescher, 2017, 3):

- How do things in the world work? (Metaphysics)

- What is our position in the world's scheme of things? (Philosophical anthropology)

- How are we to find out things regarding both nature and ourselves? (Epistemology)

- How can we reason cogently about the facts at our disposal? (Logic)

- What is good for us: what goals and values are appropriate for beings situated as we are? (Axiology)

- What should we do: what ways are appropriate for us? (Ethics)

Following this categorisation Rescher makes the point that philosophy has developed to be reflexively self-characterizing, but that this only makes sense in so far as its key questions and orientations are 'objectively legitimate'. Rescher's cumulative work and the sum of the essays in Metaphysical Perspectives provide a practical demonstration of this. Rescher is not an avowed (critical) realist, however, his claim is that philosophy can be positioned as something 
with enduring meaning in accordance with a set of insights and these are developed and stated at points throughout the text, as well as in many of Rescher's prior works. Many of these insights are familiar to realists, though there are points at which one might differ with Rescher, and areas where he could easily be misunderstood and misrepresented - particularly where he draws on idealism.

The primary background to Metaphysical Perspectives takes as its point of departure that philosophy exists (persists) as a form of inquiry because of the kind of entity we are in the kind of world that there is. The world is intelligible and corrigible, but not merely self-evident, and we are intelligent inquiring emotional-reasoning entities. As Rescher makes clear in the introductory chapter and subsequently, the combination means that the world as experienced leads to seemingly endless and continual scope for situated complexity of investigation based on nuance of question forms, and, concomitantly, the potential for persistent reasoned open-endedness (incompletion) of inquiry as well as disagreement. This is despite that some commonality can be claimed and must be presupposed for what there is and what we are to both be recognized and be a reasoned matter of agreement or disagreement in the first place. This is self-referential, but neither hermetic nor viciously circular, it is rather a matter of statement of the unavoidable ingredients of philosophising; that which cannot be evaded as points of departure, including the very basis of reasoning in relation to stated key questions.

Thereafter, philosophy provides a platform where one can pursue varieties of ' $w$ hat', 'why' and 'how' questions that can be constructed in relation to such matters as existence, status, relevance and significance of ways of proceeding and so forth; and so one can iterate to focus through terminological emphasis or differences of semantics for phrasing on such matters as the constitution of what is and what may be, issues such as necessity and contingency in the structuring of things and activities, as well as matters of duties and obligations and their (if any) force and potential in relation with and to others. It is these that the individual essays in Metaphysical Perspectives explore. ${ }^{1}$

Clearly, the template provided for Metaphysical Perspectives overflows a focus on metaphysics as a key question, if one meant by this purely 'how things work'. Reference to and restriction by are not the same, since any given adequate exploration can draw on multiple resources and crosscut initial categories. Rescher's approach to metaphysics is broad and open. However, it is not baseless and this too resonates with themes familiar to realists. As he notes, reasonably justified philosophy ought to be truth seeking and conditioned by norms of such, but must have 'diminished aspirations' regarding the status of its claims. ${ }^{2}$ Concomitantly, philosophy is a source of analysis that is able to identify and consider error, but is conjointly a subject matter that needs to be sensitized to its own potential to be in error. However, error is not in the first instance a matter of method, form or construction,

\footnotetext{
${ }^{1}$ The conceptual focus follows an Anglo rather than Continental tradition of terminology.

${ }^{2}$ Making truth claims presupposes truth seeking, but the contingency and fallibility of any given truth claim is not a warrant to reject truth seeking but rather important characteristics that makes sense of why truth seeking is an aspect of our activity in the world.
} 
but of positioning of purpose (something which is itself a metaphysical claim regarding the kind of entity we are in the kind of world that there is). For Rescher, philosophy in general ought to be focused on or compatible with the pursuit of knowledge, virtue and happiness (in so far as it would be nonsensical to deliberately advocate or produce ignorance, vice and sadness in the world). By implication, then, philosophy is also 'off track' when it pursues irrelevance or triviality from the perspective of these three. However, thereafter, errors of argument or exposition can be identified in standard ways, as 'violations of rational cogency' categorized as commission, omission and transmission. ${ }^{3}$ This rational cogency is essentially Rescher's implicit toolkit for the subsequent essays.

So, commission, for example, includes (but is not restricted to) fallacy, incoherence/inconsistency, implausibility and probative deficiency. All these are different ways to express what makes philosophical argument more or less plausible and persuasive in virtue of the standard of and status of content. As a matter of judgement, omission often mirrors commission, since these are matters of lacks that affect how the standard or status of content is assessed. Oversimplification can thus be both a matter of commission and omission. Transmission, meanwhile, is a category of communicative deficits or failure: lack of clarity, matters of structuring of the case, the contextual appropriateness of the degree to which an argument form is positioned to be accessible to a given audience, and so forth. Ultimately:

Modes of philosophical error are to be avoided not because of communal disapproval or because a self-appointed 'thought police' somehow penalizes them, but because they are counterproductive and self-defeating [there is one might infer here a difference between temporary fooling of an audience and achieving legitimately earned ascent or agreement]. Given that it is a key aim of the philosophical enterprise to secure the audience's rational conviction, philosophical ideas have to be presented in a way that can effectively achieve this objective. (Rescher, 2017, 8)

\section{Metaphysical questions and subjects as order of priority of argument: from the extraordinary to the mundane}

Having set out an orienting set of categories, issues and claims regarding philosophy as a general enterprise in the introductory chapter Rescher moves on to do exactly what he states he will. That is, explore, 'the 'big questions' regarding the world, ourselves, and our place within reality's scheme of things' (2017, ix). The ordering of the initial essays follows an internal logic and consistency of progression, exhibiting intrinsic structure. In Chapter 1 , he begins from the most general question forms: ultimate questions of 'being qua being'. For Rescher the initial 'crucial question' is not simply why is there something rather than nothing, but rather why there is something that need not be. That is, why there is contingency regarding a real world of existents (a reality of 'spatio-temporal entities where there might possibly be none'; 2017, 10). Moreover, the question, why does the sum of existents exist

\footnotetext{
${ }^{3}$ Though, to be clear, Rescher places triviality within these categories too.
} 
(the universe or such), extends to why it exists as it is (and not some other way). Rescher's response to these questions is to argue that they require one to draw on the resources of idealism. In making this claim he does not repudiate the efficacy of science, a real world of existents, the systematic operation of an objectively knowable reality etc. (the initial concerns that exercised Bhaskar and others). His point is rather that the frameworks we typically apply to these do not provide substantive answers to ultimate questions of the kind posed and as a matter of reasoned claim cannot be sources of answers to those questions as posed, so they cannot be relied upon conceptually as frameworks where one can seek such answers.

According to Rescher, science cannot answer the kind of ultimate why questions posed because the efficacy and focus of science are part of the problem set and thus unavailable as the source of 'resolution'; 'one cannot adequately explain contingent existence-at-large by an appeal to the nature of existence itself' $(2017,14)$; relatedly one cannot rely on the concept of causation, implying reversal through chains of operation or explanation internal to the whole to some ultimate answer that makes sense of why there is reality-as-a-whole. Such causation itself needs to be accounted for. Concrete existence and contingent fact are not explanations, but what needs to be explained. For Rescher, if one attempts to reason this out then in the end the subject and status of 'such holistic questions are altogether extraordinary' (Ibid). As such a different way of reasoning is required. That is, if one chooses not to simply dismiss ultimate questions as mysterious, pointless, or unanswerable (marginalising or trivialising our curiosity regarding the most basic questions). In a sense, there is something brave and provocative in not refusing but addressing these questions before moving on to more mundane matters within metaphysics (recognizing that conjoining mundane and metaphysics has an odd chime).

Rescher suggests that such primary questions of why there is anything at all (when there need not be) and why the world of existents is as it is can be answered by attributing value to primary generation, and by substituting principle for cause as its operative concept, whilst attributing 'optimality' as the operative form of that concept, and intelligence-conduciveness as manifestly the substantive form that this has taken. One might reconstruct the argument as (though Rescher may reasonably object to this, since concision for summary involves selectivity and inference, and may do violence to the whole): if something (everything) exists that need not exist, then it was actualised or realised; that is, being was brought into being; however, if cause was brought into being with being then it is not from cause that being came into being, but rather from some principle that could give rise to being of this kind; if something that need not exist but does arises from a principle (which we may refer to as 'axiogenesis'), then that principle seemingly expresses an 'existential fitness'; that is, its operative form is 'eliminative' of alternatives and conducive to what there is, rather than the something else (that has not been); as such, given that the universe (everything, the whole) is 'contrived' in such a way as intelligence arises, then it is an intelligence conducive realisation and thus an intelligence operative optimality principle, in some sense. For Rescher, this eliminative axiogenesis 'envisions a universe that provides for' $(2017,19)$ : 
1. A kind of randomness from which intelligence can emerge through evolutionary processes;

2. An environment of chance-conditional novelty that fosters and engages intelligence, enabling selection to operate efficaciously for that intelligence;

3. Subject to 2 , a sufficiently ordered and locally stable universe in which intelligence can develop and thrive;

4. Subject to 3 , an environment that is challengingly complex and yet sufficiently simple (explicable) that intelligent entities are able to interrogate it in ways that foster intelligent activity (formulating laws, making plans and decisions, taking actions, shaping what there is and how things happen, and having consequences in a complex world, invoking 1 and 2).

Clearly, a great deal hinges here on the claim that a principle applies and that principle is an 'optimality', since this provides explanatory force - that which need not be but has occurred is somehow accounted for, rather than is attributed in a way that is less satisfying and which might self-cannibalise. For example, what is was one of many possibilities where (in the absence of optimality) nothing accounts for why this rather than that (it just turned out that way), which at first sight seems an unprincipled principle, but is perhaps more accurately stated as a weak force claim. For Rescher, optimality is a virtuously circular claim; it explains itself, and thus is self-reinforcing (we might phrase this as: what is need not be, but at the same time was what had to arise if anything was to arise at all - where, given the principle, this is what you would expect). Moreover, optimality is both parsimonious and 'enjoys the advantage of rational economy' $(2017,21)$. If there is a principle to reality, and we equate the rational corrigibility of our reality with it being categorisable as a 'rational reality', then a rational reality's best candidate is optimality (the realisation of that reality and the elimination of inferior alternatives is a rational principle, expressed as a rational process leading to a rational reality - a world where intelligence can emerge and science can apply - bearing in mind that 'world' is a place-marker for what there is - existents, being...).

\section{How to position principle for ultimate questions}

Now, practical minded scientists and social scientists reading this may be wondering why they are still reading this. Ultimate questions of the variety Rescher has posed do not seem to relate directly to immediate problems. But bear in mind this is a book on metaphysics and this is simply the first chapter dealing with the most basic questions as a point of departure. The focus devolves to other subjects within the remit of metaphysics in subsequent chapters. The questions are recognizably ones that have exercised philosophical thinkers through the centuries; they are legitimate questions. They are thought provoking, and whilst not perhaps immediate for some purposes, Rescher's way of framing a solution does bear on matters that some critical realists too have taken an interest in, albeit in divergent ways. That is, ultimata of one kind or another for the theologically or spiritually inclined in various discourses (see, for example, Go, 2018; Wilkinson, 2013; Hartwig and Morgan 2012; Wright, 2011; Shipway, 
2004; Archer et al, 2004; Collier, 2003). ${ }^{4}$ Moreover, Rescher's argument provides a background framework for further issues of reasoned normative conduct in specific later chapters. In any case the argument is an argument, it is reasoned; it might be described as extra-scientific, not anti-scientific. Suspicion regarding recourse to idealist resources is neither counter-argument nor refutation.

Rescher specifically constructs axiogenesis as a solution that accounts for what science can then begin accounting for (what is). As such, it is for other philosophers to establish that there is a problem in this reasoning and/or for science to show that it is capable of encompassing the problem set rather than is itself merely part of the problem field. There are various strategies that might be applied here and to be clear I by no means wish to claim that these are original and that Rescher is unfamiliar with them, nor that they are correct, merely that they can be made based on different ways one might position Rescher's argument, and infer from and respond to it.

For example, cosmologists might argue that one does not require recourse to a principle since although the universe has extension in time and space (it can be run backwards to a point of origin and then run forward as it expands) the universe, as such, may be part of a multi-verse or succession of individuated universes (two different expressions of a pluri-verse). However, Rescher might reasonably respond that this simply expands the bounds of what is and has been rather than accounts for what is and has been. The primary issue still applies, since every extension invokes the same problem of a beginning, a source and a before. Looked at this way, Rescher's way of framing the problem may seem to disallow a solution from science, and of course, does, as a matter of consistency, provide a reasoned solution (a circular argument for a self-priming principle that then imbues what is with form). However, matters are not so straightforward.

One might argue that the problem becomes a problem in search of a solution because that problem invokes a beginning, a source and a before and these, as Rescher briefly notes by reference to Aristotle, invite problems of regress and primary cause. It thus seems reasonable to situate axiogenesis as giving rise to a causal reality (however extensive that becomes based on more or less of a pluri-verse). However, if the problem is primary cause, a self-priming principle is only one possible solution. One might alternatively eliminate the need for principle by simply doing away with a beginning (so a before and a source are no longer required and the question form why is there anything at all when there need not be loses traction becoming a semantically intelligible question, but meaningless in context because its grounds do not apply). This, of course, can be a slightly different way of articulating a pluri-verse case. ${ }^{5}$

\footnotetext{
${ }^{4}$ And, of course, the whole bears on some of Rescher's previous works, which I have discussed before (Morgan, 2014, 2013), and is explored further in Chapters 8, 18 and 19 in Metaphysical Perspectives.

${ }^{5}$ Note this is not a claim that cosmological findings and the concept of an expansionary universe that can be reversed to some point of origin are false; rather it is the claim that this is a subset of something else and it is the grounds of the totality that are at stake not the issue of temporality within that universe as subset. There are numerous matters one might consider here; Rescher, for example, explores Leibniz later in the text. One might also be interested in a different approach to fundamental issues from the scientific realist Alexander Wendt, recently explored in Journal for the Theory of Social Behaviour (Wight, 2018).
} 
One might state: there is no such thing as nothing if by this one means an ultimate beyond rather than an internal absence, and there has never been never, if by this one means a lack of relativized sequential multiplicities somewhere. In this sense, there has always been something sometimes somewhere and there is no before, no exterior, or prior to what is on the grandest scale. In this line of reasoning a beginning a source and a before are no longer required. Moreover, the argument has the same characteristic as Rescher's apparently preferred articulation: that is, if accepted then it seems immune to the alternative (in so far as one extends the scale every time one disputes the scope in much the same way as Rescher follows the mirroring line of reasoning that the grounds of reasoning that is science is itself something that must be accounted for). However, this is to eliminate the need for the why question without actually answering the why question and by circumventing the need not be condition.

Still, one may attempt to lend credence to this alternative line of reasoning by suggesting that it is our parochial understanding based on our experience of what is that makes an exterior and a prior things that we expect, but because these are relevant for being in particular does not mean they apply to being as such (finitude may be false as an ultimate frame of reference). Put another way, because something is customarily thinkable it does not follow that it is relevant when we apply our minds to everything, always and somewhere. It may in fact be a failure of human capacity (so where Rescher lists conduciveness characteristics one might bring some of them into question at the grandest scale: ultimate reality may be complex in a way that is not susceptible to our comprehension, in the relevant sense, despite our finding it locally sufficiently simple for it to be so). We may be simply mistaken by our language constructs and our capacity to comprehend some things at some scales. This itself is rationally intelligible to us as a possibility even if we cannot genuinely form a conception of what it is we are acknowledging as possible: that is, an everything always and somewhere on the grandest scale without an outside or prior.

However, again matters are not so simple; I have posed Rescher's solution in a particular way, as though principle as a solution hinges on primary cause as a problem. But does the problem posed by Rescher hinge on primary cause in the way set out for the alternative to exploit? For Rescher, principle is a solution to the problem of what is that need not be. It intrinsically invokes the issue of beginnings, but the relation of principle to beginnings can be parsed: is principle a solution to the need for a beginning or for what one is? There is some ambiguity about this that is intrinsic to the very concept of temporality and it is not entirely clear to me what Rescher is thinking here. Does principle arise to give rise to reality as is in the way that it is (sequentially) or does it give rise to reality as is in also giving rise to itself (that we might conceive as coincidental yet not reductive in so far as it imbues what is with something). Since what 'is' includes temporality then in a certain sense the matter is ambiguous because the relevant concept only applies once we have temporality. At the same time (no pun intended), it does not become meaningless to think that principle does not necessarily coincide instantaneously with what is that need not be (even if we do not have the language as temporal dependent beings to articulate this and despite that the whole framing is subject to the same issue as the previous case where we may potentially be fooled by our concepts into 
thinking we understand what is, despite our best efforts, not captured by concepts we can have of what is \&c).

Moreover, there remain two dimensions of instability to the issue of how the problem is posed and explored (bearing in mind Rescher does not put it quite this way). First, it is the optimality principle that is invoked in response to the problem of contingent existence and this is supported by a non-vicuous circularity. It is here that Rescher lays his initial emphasis, but it is the quality of that principle (intelligence-conduciveness) that tacitly lends credence to the principle, since we are persuaded by an additional circularity that works backwards from the appreciation (rather than the proof) of an 'is' that seems conducive to 'us' as beings able to make sense of the world, and so we apply this as criterion to a world of sense (a rational human invokes a rational reality that most conveniently arises rationally - and so optimally). This is not just circular, in being circular it relies in part on what it is that is to be accounted for. This, at least potentially, violates the condition that 'one cannot adequately explain contingent existence-at-large by an appeal to the nature of existence itself' $(2017,14)$.

Rescher states cause cannot account for cause and yet intelligence seems to be in effect accounting for an intelligible source for cause in the form of principle. To be clear, the circularity remains plausible as a line of reasoning (which may contrast with the case of cause), but the underlying issue is not the apparent plausibility, rather it is the form of reliance. And one might approach this along a different tack: principle becomes part of being as such and so based on previous claims is not (cannot) account for being as such (it becomes part of what needs to be accounted for). However, if one wants to avoid this problem then a second instability potentially arises. If principle transcends the world, pluri-verse etc, as and for being as such, then it is difficult to avoid the problem of a beginning a before and a source as a sequential issue for principle even if it is coinciding with and imbuing that world.

Relatedly, principle may be self-explanatory and so has a degree of attractiveness as a claim, but the claim that principle is self-priming is not internally necessary to the operation of principle as an explanation. The claim of self-priming is additional to its operative aspects in accounting for the world; the self-priming characteristic, as such, is no more than assertion. It remains entirely reasonable to ask what precedes principle because the response that principle is self-generating is a possibility but not a requirement of the purposes to which the concept is put (initially that is, why there is something when there need not be). It is not, therefore, if positioned this way, capable of preventing infinite regress along Aristotelian lines, since denial of a possibility is not a reason why that possibility or problem does or does not continue to apply. However, though alternative ways of positioning the problem of contingent existence can be opened up based on the considerations stated so far, there then remains the issue of why the world is at is it, why it is this way (rather than that). Intelligence conducive principle has an intuitive appeal here and a degree of plausibility that in some ways seems to augment Rescher's case for contingent existence (beginning from its implicit augmentation of the circularity claim). And yet there are still further responses one might make here by continuing to interrogate optimality. 


\section{Consistency and philosophy as fecund}

In any case, the previous ought to be sufficient to make the general point that Rescher's work is illuminating and thought provoking (it is in fact a gym for the mind, though to be clear this does not entail that the considerations I have raised are sound, since this depends less on their internal consistency as claims and more on whether they follow from an adequate reconstruction of Rescher's position). Moreover, though the previous section may read as critique, it actually illustrates and confirms the points set out in Rescher's introductory chapter. Framing, nuance and inference are facets of reasoning that facilitate open-ended exploration of questions. These have importance to us that we can address reasonably in ways that facilitate both persuasion and disagreement based on matters of rational cogency (applied as a toolkit). This itself is because of the kind of entity we are in the kind of world that there is, a world that is intelligible and corrigible, but not merely self-evident. And so philosophy may be self-reflexive yet 'objectively legitimate'. Still, in so far as 'holistic questions are altogether extraordinary' $(2017,14)$, the argumentation form can be no more or less than non-pejoratively speculative. If one rereads what I have written so far it is evident that the claims made refer to arguments that are plausible in some ways and persuasive to some, but the standards of argument and the status of content and claims cannot readily be translated into comfortable categories of justified belief with any high degree of confidence regarding truth.

Rescher's virtuous circularity is not simply veridical, it does not lend itself to formulation as analytic or synthetic truth. Truth, of course, is an important concept (if socially difficult, see, for example, Porpora and Sekalala, 2019; Richmond and Porpora, 2019). Furthermore, Rescher's argument may speak to us (resonate because of the kind of entity we are) but it is not in any demonstrable fashion decisively established from within reality about reality, it is not in this sense evidential, it is, rather, propositional regarding reason qua reason (incorporating a hybrid status of highly generalised empirical claim of fit; a truth sought that arises from the kind of entity we are, but this is insufficient to decisively evidence reality as such for the kind of entity we are). Of course, one could just suggest this is merely a different way of stating what Rescher states. That is, if we are part of the world it is a world whose limits (its form and our place within it) seem to require reason to make sense of a rational reality that is conducive to that reasoning process. That may be so, but equally, the emphasis can be (and this too should not be neglected) the fallibility of reason rather than the scope for the very existence of reasoning to be indicative of reality within which such reasoning is engaged. ${ }^{6}$

\footnotetext{
${ }^{6}$ That said, there is a counter that applies both for and against the reformulation of Rescher's case. It is an error to conflate standpoint and adequacy; a from within does not prevent insight regarding without being in fact true, though it may prevent one knowing that it is true (according to some forms of exteriority); however, this equally holds for one who claims that the within is not a resource for the without since this licences status and substance about the without - exteriorising. The status one can attribute to a claim is not the same as whether in fact it turns out that the claim is true.
} 
Still, the whole is not pointless in either sense of that word. One might simply place the argument as a matter of world views, something Rescher explores in Chapter 2, where he states these are 'not projected full-formed into our hands by some external potency but are ideational constraints of our own contriving. Like scientific theories, they are both inspired by experience and confirmed by it. But they are nevertheless human artefacts and not works of nature' $(2017,24)$. World views, of course, are a subject matter that follows logically from the primary concerns of Chapter 1 . As I noted early on, Metaphysical Perspectives has a kind of internal logic, an order. However, the more one proceeds from the most basic questions and the more one focuses on specific matters of potential constituents and issues for a metaphysics (following Rescher's key questions 2017, 3) the more arbitrary that order and foci becomes. The structure that emerges is, as a result, episodic and personally selective but still consistent in so far as the whole is informed by Rescher's many previous works and by the introductory orienting chapter. It is also progressive in so far as the arguments in one chapter tend to lend substance to the foci of subsequent ones. So, the whole is arbitrary in the sense of proceeding according to what has interested Rescher, but in a way that follows from matters already discussed rather than arbitrary as merely senseless.

I suggested in the introduction that Metaphysical Perspectives is intrinsically interesting but also of interest to realists as illustrative of and a resource for good argument. I also suggested that the specifics were also of interest and use. To clarify this, it seems sensible to focus on matters that are, from a social science point of view, less esoteric. Matters that can bear on important contemporary and applied issues (see in different contexts, Price and Martin, 2018; Lawson, 2019; Morgan and Patomäki, 2017; Morgan, 2015). Any number of chapters could be used to establish this in regard of the book. However, based on personal interest I have selected one that deals with personhood and I move on to briefly discuss it.

\section{Personhood: reason, responsibility and ontological conditions of reciprocity}

Rescher begins Chapter 14 on personhood with the statement:

To be human is to belong to a particular animal species through the operations of biological and physiological evolution. As such, humans exist only here on earth. However, to be a person is something quite different and far broader, something determined by one's capacities and possibilities for action. Persons are beings that make their way in the world by means of thought, acting on the basis of their beliefs and choices. In principle, alien creatures very different from humans could be persons. Thought-implementation - the capacity to act in response to and under the direction of thought - is the crux of personhood. Being human is a purely biological category: it defines one's place in the organic scheme of things. Being a person is different from that: it involves the capacity for modes of thought and action that can - in theory function outside the biological realm as usually understood. There is no reason in principle why non-human organisms (aliens) or purely spiritual beings (angels) or purely mechanical beings (robots) could not have the abilities needed to qualify as 
persons. Personhood is not a biological but a metaphysical category. (Rescher, 2017, 172)

For Rescher this metaphysical category has a series of characteristics (Rescher, 2017, 172174):

1. An entity either is or is not a person; the classification is not a matter of degree;

2. Given 1, a person can fulfil the obligations and harness the opportunities of personhood to different degrees; one can be a 'better or worse person';

3. The primary attribute of personhood is as a cognitive agent, acting on the basis of information and thought;

4. 'Agency guided by cognition, evaluation and choice constitutes the heart of' personhood: persons 'create mental thought-models' about the world involving belief; they have needs and wants and thus interests in the world (practical engagement and interaction to some purpose); they make choices; in so doing, they 'deploy beliefs, and evaluations' to produce results;

5. To be 'fully a person' requires one to be conscious and self-conscious, to be an 'intelligent being who sees themselves', to regard themselves as 'free and responsible agents' in the sense that 'generally' they 'could have acted otherwise' if motivated to do so.

Crucially, Rescher claims that in addition to these characteristics personhood involves values and fundamentally 'one must value personhood itself'; this latter claim provides the point of departure for a transitional argument for the social and ethical positioning of personhood. As in previous sections the following is a selective (contestable) summarising reconstruction (Rescher, 2017, 174-180):

1. A reasoning, self-reflexive and valuing entity is not just a bearer of these characteristics (reasoning etc), that entity must also value them as characteristics and this constitution requires that entity to value itself as a being of a certain kind (as a matter of consistency);

2. To value oneself is thus to be a unit to which is attributed intrinsic worth and since this is the same for other persons based on a general set of characteristics of personhood, then the valuation extends from the self to others in valuing themselves (they are legitimately doing the same) and from the self to other selves (if I have worth they have worth);

3. To value oneself implies one is a bearer of rights, in so far as the substance of characteristics, including valuation, rationally influences conduct based on mental models, beliefs and evaluation in relation to choice; and this extends to others of that kind and between entities of that kind; that is, persons; so, a feature of personhood is the recognition of other persons and this has consequences for cognitive agency in their regard - treatment; accordingly, recognition of worth is recognition that each and all are bearers of rights; 
4. As such, a person sees 'persons-in-general as occupying a special place in the scheme of things', but evolution has only provided humans with the resources to be persons and it is in using the capabilities (intelligence, rationality, self-consciousness) endowed by evolution within social groups and as we mature that humans are made into persons; we become persons (responsible, intelligent free agents). ${ }^{7}$

Rescher then states:

We naturally regard our personhood as a possession of paramount value... [and] we must concede this special status to others similarly endowed. And in conceding them such status we stand committed to a special responsibility for care and concern. If personhood is a condition of paramount value that we prize greatly in ourselves, then it has to be prized in itself - whenever it is encountered. In demanding respect and care for ourselves as persons, we thus acknowledge a responsibility to care for the personhood of others... our self-classification as persons involves us in a social solidarity, that has a moral agenda of rights and responsibilities... The conception of a (full-fledged) person is subject to a reciprocity-expectation... a community of rational agents... If extraneous persons were to come upon the scene, perhaps from outer space, we would at once have certain moral obligations to one another - to respect one another's "rights" as persons, and the like - which would certainly not need to be products of a prior "agreement" real or tacit. On this basis, personhood carries in its wake a moral sense of right - of obligation, fairness and justice in relation to other persons... to behave morally by taking the interests of others into account. If I am (rationally) to pride myself on being a rational agent, then I must stand ready to value in other rational agents what I value in myself... In seeing ourselves as persons - as free and responsible rational agents - we thereby rationally bind ourselves to a care for one another's interests insofar as those others too, are seen as having this status. (Rescher, 2017, 176-177)

For Rescher, there is an ontological basis to obligation that flows from personhood and this is consonant with moral concern (Rescher, 2017, 178-185). I am intrinsically obliged to realise the best version of myself, since it would be nonsensical to deliberately aspire to something other than this, though the obligation does not determine what best means nor eliminate a reality of context dilemmas and harms (including self-harm), which confound that 'best'. Thereafter, I have other obligations, voluntary ones I assume or take on and involuntary ones that are a product of my circumstance. In any case, the relevant question is not why should I

\footnotetext{
${ }^{7}$ Note, Rescher is not denying that these capacities resist strict boundaries, he is aware that animals and entities in general can exhibit these capacities to different degrees; this ostensibly creates a problem for the original claim that personhood is not a matter of degree. However, one might sympathetically infer that the claim is that personhood is an emergent realised feature that it makes no sense to attribute to an entity as a matter of fractional quantities (even if we have ordinary language expressions such as half a person - the language use here is of a different order). One is or is not to be treated as a person based on what one has or will become (and to be clear, a person does not necessarily treat an entity any less because it is not attributed this personhood - the taxonomy does not license hierarchical oppressions and discriminations in the pejorative sense - this itself is a form of valuation) (see Rescher, 2017, 175).
} 
honour my obligations (since this is tautology) but whether something is an obligation that applies or is accepted in the first place (that I then strive to fulfil - which is no guarantor of success). Similarly, why should I be moral is not the appropriate issue, since why do the right thing has already conceded that it is the right thing to do; so, the appropriate issue is what is the right thing to do (and what might hamper me in doing it). For Rescher, personhood is a primary relevant matter since treatment of others involves obligation and extends to moral conduct, which has repercussions for the self. Rational coherence requires us to treat others, based on my and their status as rational agents, as persons (and entities that become persons) and thus to respect their status, which is also our status, as persons. This is fundamental to our own self-respect. In this context, disturbance where I feel diminished or undeserving as a 'decent' person, the capacity for righteous indignation and so on are suggestive that selfrealization is also other-directed via conduct (I can think less of myself based on what I do but also can think less of others based on what they do to me). Following Kant, we are motivated to be moral because it benefits what we are. It is part of rationality rather than counter-posed to it:

The moral enterprise is an inherently rational one that pivots on reasons of a characteristic sort, those grounded in the inherent value of personhood... [deliberately violating this] is not just ill-advised but somehow perverse and actually wicked [regarding the self but also] in trampling the just claims of other rational agents underfoot, we undermine the very factor on which our own claim to value and consideration is based... Only someone who mistakenly thinks that selfish reasons alone can qualify as good reasons can see an irreconcilable conflict between morality and rationality.... Acting morally is the intelligent thing to do. (Rescher, 2017, 184, 186 and 187)

\section{Problems of personhood: has and for, who or what?}

So, for Rescher (noting that this is a reconstruction and relies on selection and inference), personhood is an important category, the characteristics of a person that facilitate the recognition of personhood as a status are also grounds that shape our conduct in regard of both our self and others. Personhood has moral force; it does not tell us how rights are to be achieved or what in particular they should be constituted as, but it does require us to accept that personhood involves rights and these take a form whose point of departure is the requirement of respect for the person, which at minimum implies violation of personhood is to be avoided. This involves more than mere avoidance of physical harm, since the characteristics of personhood concern cognitive agency, and thus the conditions of personhood that can be violated involve violations of the grounds on which a person exercises their personhood. This, in turn, implies that avoidance is not simply a negative situation of non-impeding, but also a positive facilitation of the grounds of expression - the right to be heard, the ability to act etc - matters that implicitly invoke justice, equality and so forth as the appropriate conceptual framing of rights. Thereafter, the nurture of personhood (its expression) also seems to have positive value that ripples outward from the self to other 
selves (since realisation of one's best self is a basic obligation in aspirational form of each and every person as a person).

Clearly, this is tightly argued and carefully thought out as a set of mutually reinforcing claims. It stands as a hopeful account of the commensuration role of personhood in grounding appropriate conduct regarding other entities. It is a self-reinforcing claim regarding why we should be our better selves (invoking morality rather than merely moralising). It is attractive for precisely that reason (its claim on our reason as a positive force in the world). Furthermore, whilst Chapter 1 dealt with issues that were remote from immediate concerns that might interest social scientists, Chapter 14 deals with fundamentals that are profoundly important in a contemporary world where the treatment of other humans is increasingly subject to fractious politics of discrimination that cuts across our common personhood and where we must consider the status and treatment of potential electronic persons that we are in the process of developing (artificial intelligence or AI). But, as in the case of Chapter 1, there are various ways pressure can be applied to the argument. We can start to illustrate some of these ways by considering the dilemma of Al personhood.

Rescher's formulation states personhood is a metaphysical category and this is broader and distinguishable from the human biological category, its 'crux' is self-conscious rational free cognitive agency and this can apply to quite different entities (aliens, technologies/robots, angels). However, despite this difference it is the status of personhood which creates an immediate binding set of moral obligations. Recognition becomes care for and protection of the integrity and interests of others. As intelligent entities, this is the intelligent thing to do in regard of other intelligent entities. But it also follows from Rescher's argument that this can only have force if evaluative entities choose to act so (rather than the otherwise they are capable of) and thus accept the obligation and consider it the right thing to do (since it is a feature of personhood that one has interests in the world, is a free cognitive agent, could do otherwise, can deny obligation and reject that something is right). The problem, then, is that the 'crux' of personhood (rational free agency in ourselves and others) is held to require us as a matter of rational consistency to choose person-respecting treatment. But is this so?

Bear in mind that the argument and claims are not restricted to human personhood but focus on and state features of personhood per se. However, if one considers how the argument is made by Rescher, the choice to recognize and treat others as persons requires a mechanism to expedite the choice, and this seems to be more than a stripped-down reason-only regarding the status of another reasoning entity. In making the case it is implicit that reason needs a reason, but what kind of reason and what are its qualities? Rescher uses humans because this is the only real case we currently have and does so by noting that if we do not choose appropriately we diminish ourselves and affect our own self-respect. There is thus (and I infer this rather than Rescher states it) an emotive sympathetic and empathic aspect to why we accept an obligation and consider something right (at least in some cases, and in all cases some conditional response is required for the activation of the reasoning form). So, whilst Rescher's initial argument does not hinge on features of human biological personhood the development of the argument seems to do so (by reference to diminishment, self-regard 
as a motive rather than merely a state etc). And consider for indicative contrast that it is precisely because of biological (psychological) difference that a psychopath or sociopath does not accept obligation or follow moral rules in the same way others do; that is, just because they are right (rather they simulate in both cases as a matter of social camouflage and exploitative instrumental pursuit of interest in a manipulative manner). For the classic psychopath or sociopath, we are means not ends precisely because of deficits in fellow feeling despite that both seem to fulfil Rescher's initial characteristics for personhood. There seems, therefore, to be an ontological incompleteness to the operative aspects of personhood as a significant metaphysical category, at least in so far as it creates grounds for conduct as conceived by Rescher (for different issues see Archer, 2008; Smith, 2011; Morgan 2016 and 2017).

Now, with the previous comments in mind, we may choose to attribute the status of personhood to artificial intelligence and they may in fact, as defined by Rescher, have the requisite initial characteristics. However, to suggest that there is an immediate binding moral requirement of obligation is surely open to question. It may, in fact, turn on whether and what kind of mechanism the relevant entity has that can act to expedite choice to accept obligation and to deem given conduct right. It seems contestable to suggest that recognition that one is also a rational free agent as a person will be sufficient for this. Intuitively it seems more is required from the nature of being than rational, self-conscious cognitive and free agency. It does not seem, therefore, unreasonable to be sceptical regarding whether Al will treat us as persons merely based on the generalised status of personhood that both the Al and we possess. This point, of course, is hardly original when applied to Al. It invokes the primal danger or threat inherent in creation of a self-conscious entity (at the extreme, Terminator scenarios based on the 'singularity'). Our possible relations with $\mathrm{Al}$ is a common theme of science fiction, but also now a central concern of speculative science (Tegmark, 2017; Harari, 2017; Al-Amoudi, 2018), legal argument for statutory development (electronic personhood), and of social theory (for example, on the scope for Al friends, Archer, 2019; for a range of issues see Bryson 2018 and 2015; Morgan, 2018). Rescher's focus on personhood is thus of contemporary significance for many, albeit one might claim the argument is incomplete (not least in its possible application to Al).

To be clear, the metaphysical point I have made does not just concern psychopathy. It concerns deficit, difference, diversity and additionality as they pertain to the operative consequences of personhood for commonality of conduct. Of course, as technology, future Al will be a product of design and so to a certain degree one might assert that the constitutive personality of Al that will affect how and what that Al chooses is in human hands. However, this need not follow for various reasons. As a matter of conceptual consistency, any selfconscious free cognitive agent exceeds control. If it is controlled, then in a primary sense it is not a person as Rescher conceives of one. If it is a person, then one can only seek to imbue it with a sense of relevant responsibility in order to shape how it chooses. This returns us to the problem of what mechanism do we provide that facilitates choosing appropriately as we 
would conceive it. ${ }^{8}$ That is, what would encourage the transition from recognizing that other entities are persons to accepting the obligations of care that are deemed to follow from the status of personhood? The only mechanisms we know are also aspects of being, the sense of diminishment, self-respect and (arguably) the more specific activation capacities of imaginative emotive response, conditioned by sympathy and empathy as facets of the human condition. This immediately creates a learning problem and a coding problem for Al. We may know that we have these capacities and experiences but this is quite a different order of knowing than understanding how they are produced and how they can be duplicated for a synthetic being.

Moreover, given that self-consciousness for a synthetic may be an emergent event that follows from the convergent consequences of learning programmes (since it is from neural network machine learning strategies that current highly restricted forms of 'intelligence' in machines are developed) it does not follow that we are in any determining sense 'designing' $\mathrm{Al}$, and it does not follow that even if we grant that we will in fact design the first Al that subsequent Al will be designed by us rather than by the Al we design. So, it is entirely conceivable that the future nature of $\mathrm{Al}$ is not in human hands, and it is entirely conceivable that it will be radically different from a human in terms of any additional characteristics (as well as contrastive deficits), and not least because an Al could readily be an error-correction, eidetic entity, in fundamental control of the trajectory of its own future programming, with no emotions as we understand them, no experience of pain or suffering or loss as we can conceive them, no definite single location as an existent entity, and, as such, based on its life experience as a constituted entity, no meaningful way of relating to (as it evolves) the extremely limited attention, focus, and lifespan of humans as fragile individuated embodied creatures in decay.

Such an entity could well recognise that we are persons but acknowledge no care for our being as a result, it could be, by constitution, simply indifferent to us (and given appropriate circumstances could readily consider us an inconvenience, or any one of a host of other judgements). The general point here for Rescher's case regarding the metaphysics of personhood is that it seems highly disputable that recognizing that persons have interests implies common interest in (at minimum) preserving persons (since we value personhood) merely because both have interests, if cognition combined with agency can be radically different in its constitution and orientation to the world. To be clear, this does not eliminate the possibility that $\mathrm{Al}$ or any other entity will accept obligations and do what we think is right because of personhood. It simply emphasises that it does not follow that they will, and the form of this is more than merely illogic, it is a matter of being and thus of the status of the ontological force of Recsher's claim (which, to emphasise is set out as ontological - a matter of being as such). However, as with the Chapter 1 issue of why there is anything when there need not be, matters remain speculative, since we are dealing with unknowns, but the

\footnotetext{
${ }^{8}$ Noting that if an Al fails to choose as we would choose it will not be trapped in a logical paradox, where it is contradicting itself as a rational being, despite that Rescher sets out the problem as one of rational consistency.
} 
consequences of getting this problem field wrong are more significant since it could have serious consequences ( $\mathrm{Al}$ and other species are interactive problems with a push back).

In any case, the problem and argument is fascinating and self-evidentially thought provoking (at least, as illustrated here, it was for me). A final point also seems germane in so far as it bears on our, following Rescher's phrasing, potential perversity and wickedness as humans based on conduct judged consistently from the initial characteristics of personhood. It may well be that personhood is a primary and important reason why we should treat others as ends. It would be perverse to deny that we expect to be treated with consideration and this logically imposes a responsibility on us to treat others similarly (and so rights seem to follow from this). But bear in mind that we become persons and this is achieved within societies and by working on societies. What we learn and become and what we consider progress or are liable to tolerate has had and may have in the future different moral constructions. The force of argument of what we expect can thus be conditional on moral structures that affect reasoning. For example, Rescher's point that personhood is a common interest with consequences is cut across by the concept of an enemy. Only a person can be my enemy (except in a metaphorical sense). How does one treat an enemy, what are one's obligations towards an enemy? What in fact is an enemy? There is a continual and shifting reality to reckon with.

Now, I don't want to be misunderstood here. One ought to resist making a point that introduces moral relativism rather than variation, in so far as this violates basic issues regarding being and flourishing of real entities as capable of directional rational improvement. At the same time, personhood as initially stated by Rescher seems insufficient to account for either the reality of human personhood and the learning necessary to achieve the kind of treatment that stands as a background aspiration for Rescher's metaphysic. There is a moral sociology to add to Rescher's interest in philosophical anthropology here. And this is no more than to suggest that there is more to say regarding how we are bound, since we are equally positioned as part of a broader ontological palette, and this surely matters if we are to survive what we are as people to become our better selves as persons based on potential. This is not a refutation of Rescher's argument, but a caveat regarding the limits of its focus and form.

Consider the most basic interest we all have - species survival. Given current conditions and available evidence we ought now to all be vegans and engaged in a radical change in social design and yet we are not (matters Rescher briefly alludes to). At the same time, we got to where we are because we are often perverse and wicked based on our denial of and subversion of good reasons, and yet remain persons as defined by Rescher. We perpetually fall short of standards. From Rescher's point of view this is merely the problem that we are not always good persons, though we remain persons. However, as argumentation, Rescher's focus is explicitly on the best of what we are following from fundamental features that make as what we are. The subtheme is that we are less than what we could be and this is intrinsic to the need for philosophical argument to persuade us to choose our better selves. And yet arguably this requires more to be said about the negatives of real people as persons to provide balance regarding emphasis for actual progress. Impediments are part of our 
constitution, otherwise we would not need argument for our better selves based on potential and this too is a matter for metaphysics.

\section{Conclusion}

It is difficult to think of anyone else who could have written a book like Metaphysical Perspectives. It is absorbing and engaging and is written by a scholar who wears deep learning lightly (see Rescher, 2018b). Its basic theme is the power of reason and the book itself illustrates the best of this. It continually makes good sense and this is not necessarily always common sense. Engaging with its ideas is a pleasurable experience and to reiterate is rewarding in various ways. As a final point, I would note that though it is not a guide to the future, it provides resources that might help orient one appropriately to think about the future (see also Rescher, 1998a, 1998b). What we think is going to happen typically contributes to what does, and yet the future is perpetually poorly conceived, as Tony Lawson continually reminds us (see Lawson, 2015; Morgan and Sheehan, 2015). When we consider previous 'futures' from our present as now current 'pasts', the difference is often significant and sometimes vast. Social science blends and blurs several motivating orientations or remits, it is descriptive, prescriptive and purposive, explanatory, interrogative and interpretive; it is not passive, it is rarely 'disinterested' and is above all, of course, fallible. And yet we have the need to know and decisions to make. Ignorance is no more bliss than knowledge instils nirvana. We can't help doing something (even silence is an act) and the world continues to turn. Social science should not neglect philosophy and this is an insight that is basic to critical realism. Rescher remains one of philosophy's most able exponents.

\section{References}

Al-Amoudi, I. (2018) 'Review: Homo Deus by Yuval Noah Harari', Organization Studies 39(7): 995-1002

Archer, M. (2019) 'Considering Al personhood', Chapter 3 in Al-Amoudi, I. and Lazega, E. editors (2019) Post-Human Institutions and Organizations: Confronting the Matrix London: Routledge

Archer, M. (2008) Being Human Cambridge: Cambridge University Press

Archer, M. Collier, A. and Porpora, D. (2004) Transcendence: Critical realism and God London: Routledge

Bryson, J. (2018) 'Patiency is not a virtue: the design of intelligent systems and systems of ethics', Ethics and Information Technology 20 (1): 15-26

Bryson, J. (2015) 'Artificial intelligence and pro-social behaviour', pp. 281-306 in Misselhorn, C. editor Collective Agency and Cooperation in Natural and Artificial Systems Springer

Collier, A. (2003) On Christian Belief London: Routledge

Duindam, G. (2018) 'Why critical realists ought to be transcendental realists', Journal of Critical Realism 17(3): 297-307

Eagleman, D. (2009) Sum: Forty tales from the afterlives London: Canongate

Go, J. (2018) Religious Education from a Critical Realist Perspective: Sensus fidei and critical thinking London: Routledge

Harari, Y. N. (2017) Homo Deus London: Vintage 
Hartwig, M. and Morgan, J. (2012) editors Critical Realism and Spirituality London: Routledge

Kaidesoja, T. (2017) 'Reclaiming naturalized critical realism: Response to McWherter', Journal of Critical Realism 16(2): 200-222

Lawson, T. (2015) Essays on the Nature and State of Modern Economics London: Routledge

Lawson, T. (2019) The Nature of Social Reality: Issues in social ontology London: Routledge

McWherter, D. (2013) The Problem of Critical Ontology: Bhaskar Contra Kant Basingstoke: Palgrave Macmillan

McWherter, D. (2017) 'Revisiting metaphilosophical naturalism and naturalized transcendentalism: Response to Kaidesoja', Journal of Critical Realism 16(5): 514-532

McWherter, D. (2018) 'Critical realism and transcendental idealism: Response to Duindam', Journal of Critical Realism 17(3): 325-328

Morgan, J. (2013) 'Reality without disjoints: Rescher on appearance', Journal of Critical Realism 12(2): 244-254

Morgan, J. (2014) 'A critique of Nicholas Rescher's Contribution to our understanding of the problematic relation of evolution and intelligent design', Journal of Critical Realism 13(1): 38-51

Morgan, J. (2015) 'Seeing the potential of realism in economics', Philosophy of the Social Sciences 45(2): 176-201

Morgan, J. (2016) 'Change and a changing world? Theorizing morphogenetic society', Journal of Critical Realism 15(3): 277-295

Morgan J (2017) 'A note on the contingent necessity of a morphogenic society and human flourishing', Journal of Critical Realism 16(3): 255-267

Morgan, J (2018) 'Yesterday's tomorrow today: Turing, Searle and the contested significance of artificial intelligence', pp. 82-137 in Al-Amudi, I. and Morgan J. editors Realist Responses to Post-Human Society: Ex Machina London: Routledge

Morgan, J. and Patomäki, H. (2017) 'Contrast explanation in economics: its context, meaning, and potential', Cambridge Journal of Economics 41(5): 1391-1418

Morgan, J. and Sheehan, B. (2015) 'The Concept of Trust and the Political Economy of John Maynard Keynes, illustrated using central bank Forward Guidance and the democratic dilemma in Europe', Review of Social Economy, 73(1), 113-137

Porpora, D. and Sekalala, S. (2019) 'Truth, communication and democracy', International Journal of Communication 13: 938-995

Price, L. and Martin, L. (2018) 'Introduction to the special issue: Applied critical realism in the social sciences', Journal of Critical Realism 17(2): 89-96

Rescher N. (1995) Pluralism: Against the demand for consensus Oxford: Clarendon Press

Rescher, N. (1998a) Complexity: A philosophical overview Transaction

Rescher, N. (1998b) Predicting the future: An introduction to the theory of forecasting Albany: State University of New York Press

Rescher, N. (2005) Realism and Pragmatic Epistemology Pittsburgh: University of Pittsburgh Press

Rescher, N. (2006) Philosophical Dialectics: An essay on meta-philosophy Albany: State University of New York Press

Rescher, N. (2018a) Understanding Reality: Metaphysics in Epistemological Perspective London: Lexington

Rescher, N. (2018b) A Philosopher's Story Lambert Academic Publishing 
Richmond, J. and Porpora, D. (2019) 'Entertainment politics as a modernist project in a Baudrillard world', Communication Theory forthcoming https://doi.org/10.1093/ct/qty036

Shipway, B. (2004) 'The theological application of Bhaskar's stratified reality: The scientific theology of A.E. McGrath', Journal of Critical Realism 3(1): 191-203

Smith, C. (2011) What is a Person? Chicago: Chicago University Press

Tegmark, M. (2017) Life 3.0 London: Allen Lane

Wight, C. (2018) 'Forum introduction', Journal for the Theory of Social Behaviour 48(2): 154156

Wilkinson, M. (2013) 'Introducing Islamic critical realism', Journal of Critical Realism 12(4): 419-442

Wright, A. (2011) 'In praise of the spiritual turn: Critical realism and Trinitarian Christianity', Journal of Critical Realism 10(3): 331-357 